\title{
SURGICAL TREATMENT OF THORACIC DISC HERNIATION USING THE ANTERIOR APPROACH
}

\author{
KIYOSHI OTANI, SADAAKI NAKAI, YOSHIKAZU FUJIMURA, SHUNICHI MANZOKU, KEIICHI SHIBASAKI \\ From the Department of Orthopaedic Surgery, National Murayama Hospital, Tokyo
}

\begin{abstract}
Between 1970 and 1980, at the National Murayama Hospital, 15 patients with thoracic disc herniation underwent total discectomy by an anterior approach, followed by interbody fusion using autogenous iliac bone. The results in all 15 patients were favourable. The extrapleural approach to the thoracic vertebrae is preferred because of simplified postoperative care and easier prevention of respiratory complications and is considered safe and suitable for the surgical treatment of symptomatic thoracic disc herniation.
\end{abstract}

Herniation of a thoracic disc is relatively uncommon and is not recognised as often as herniations of the cervical and lumbar discs (Love and Keifer 1950; Logue 1952; Kite, Whitfield and Campbell 1957). In addition, the various clinical pictures occurring with thoracic herniations are not characteristic and can lead to a delay in diagnosis (Tovi and Strang 1960; Love and Schorn 1965). Herniation in this region is of particular importance because of the serious disorders of nervous function which result from anterior compression of the spinal cord. Early diagnosis and prompt surgical treatment are imperative because of the progressive and serious neurological deficit which results from delay (Kite et al. 1957; Love and Schorn 1965; Otani et al. 1977).

This paper describes our experiences in the surgical treatment of thoracic disc herniation using the anterior approach.

\section{MATERIAL AND METHODS}

Fifteen patients with thoracic disc herniation have been treated surgically using the anterior approach at the Murayama Hospital during the 11-year period from 1970 to the end of 1980 (Table I). The age of the patients at operation ranged from 28 to 75 years with a mean of 49.5 years; there were 13 men and two women (Fig. 1). The site of herniation was $\mathrm{T} 11-12$ in seven, $\mathrm{T} 12-\mathrm{Ll}$ in three and single examples were seen at T4-5, T6-7, T7-8, T8-9, and T10-11. A convincing history of trauma was obtained from two patients only.

Symptoms and neurological evaluation. The duration of symptoms varied greatly, ranging from a few hours in a patient with a rapidly developing paraplegia, to a period of five years and three months in a patient with a long-standing history of periodic numbness of both legs. Signs and symptoms of paraplegia were found in all 15 patients. All complained of muscle weakness in both legs and some difficulty with gait, and five patients were unable to walk at all because of severe weakness of the legs. Sensory disturbances were present in all 15 patients: these were bilateral in 12 and unilateral in three, and usually presented as diminution of sensation rather than as complete loss. The patellar and the Achilles tendon stretch reflexes were brisk bilaterally in 10 patients and sluggish or absent in five. Complaints of symptoms referable to the urinary system were noted in 13 ( 87 per cent) of our patients, and consisted primarily of incontinence or retention. Three patients with a history of rapidly developing paraplegia complained of constipation or faecal incontinence.

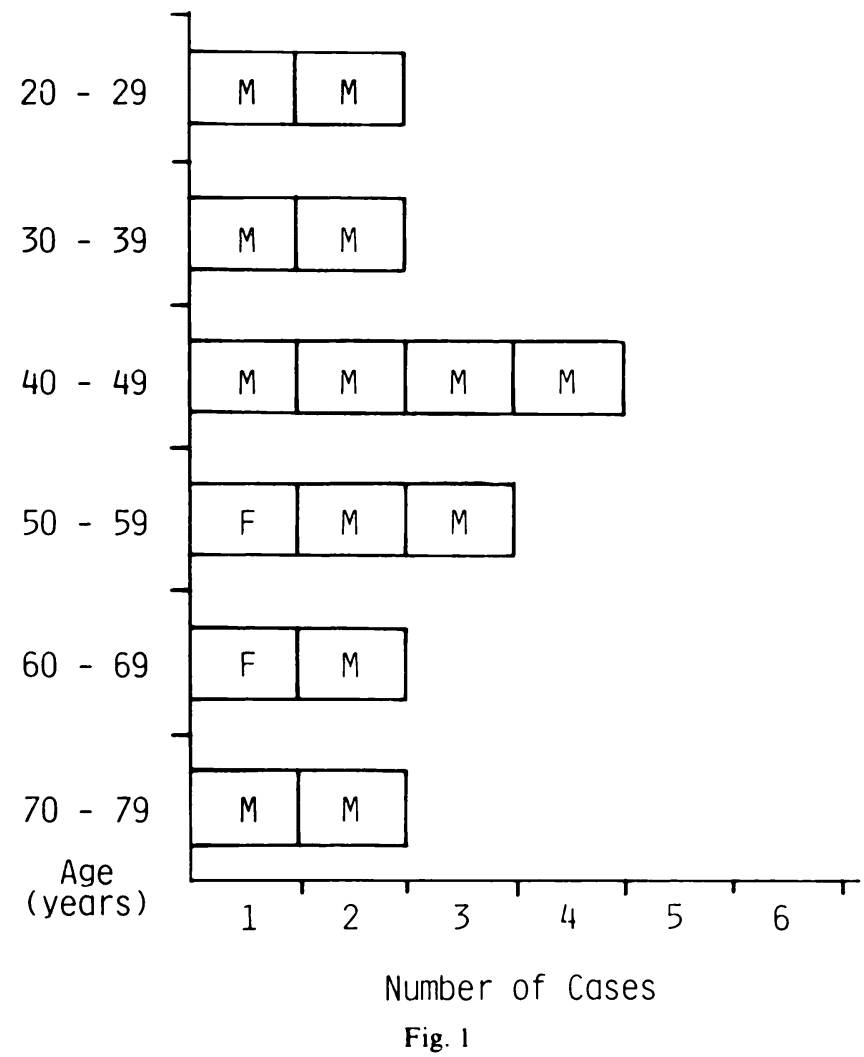

Age and sex distribution in 15 cases of thoracic disc herniation.

K. Otani, MD, Senior Orthopaedic Surgeon

S. Nakai, MD, Senior Orthopaedic Surgeon

Y. Fujimura, MD, Senior Orthopaedic Surgeon

S. Manzoku, MD, Senior Orthopaedic Surgeon

K. Shibasaki, MD, Senior Orthopaedic Surgeon

Department of Orthopaedic Surgery, National Murayama Hospital, 2-37-1 Gakuen, Musashimurayama-shi, Tokyo 190-12, Japan.

Requests for reprints should be sent to Dr K. Otani.

(C) 1982 British Editorial Society of Bone and Joint Surgery 0301-620X/82/3055-0340 \$2.00 
Table I. Clinical details in 15 cases

\begin{tabular}{|c|c|c|c|c|c|c|c|c|c|c|c|c|c|c|}
\hline $\begin{array}{c}\text { Case } \\
\text { number }\end{array}$ & Age (years) & Sex & $\begin{array}{c}\text { Sensory } \\
\text { loss }\end{array}$ & $\begin{array}{c}\text { Weakness } \\
\text { in both } \\
\text { legs }\end{array}$ & Gait & $\mathbf{R}_{\mathbf{R}}^{\mathbf{I}}$ & $\begin{array}{l}\text { Leg r } \\
\text { SR } \\
\text { L }\end{array}$ & $\begin{array}{c}\text { eflexe } \\
\text { AS } \\
\text { R }\end{array}$ & R & $\begin{array}{c}\text { Urinary } \\
\text { symptoms }\end{array}$ & $\begin{array}{l}\text { Duration } \\
\text { of symptoms }\end{array}$ & Myelography & Level & Result \\
\hline 1 & 50 & $\mathrm{~F}$ & Bilateral & Moderate & Difficult & & $\uparrow$ & $\uparrow$ & & Moderate & 9 years & Partial block & T11 12 & Good \\
\hline 2 & 42 & M & Unilateral & Moderate & Difficult & $\uparrow$ & & $\uparrow$ & $\uparrow$ & Mild & 1 year & Partial block & TII 12 & Excellent \\
\hline 3 & 58 & $\mathbf{M}$ & Unilateral & Mild & Difficult & $\rightarrow$ & $\rightarrow$ & $\downarrow$ & $\downarrow$ & Mild & 5 years 11 months & Complete block & $\mathrm{T} 12 \mathrm{~L} 1$ & Excellent \\
\hline 4 & 57 & $\mathbf{M}$ & Unilateral & Moderate & Difficult & $\rightarrow$ & $\rightarrow$ & $\downarrow$ & $\downarrow$ & None & 3 years & Partial block & $\mathrm{T} 12-\mathrm{LI}$ & Good \\
\hline 5 & 36 & $\mathbf{M}$ & Bilateral & Moderate & Difficult & $\uparrow$ & $\uparrow$ & $\uparrow$ & $\uparrow$ & Mild & 2 years & Partial block & $\mathrm{T} 1112$ & Excellent \\
\hline 6 & 48 & $\mathbf{M}$ & Bilateral & Moderate & Difficult & $\uparrow$ & & $\uparrow$ & $\uparrow$ & Mild & 6 months & Partial block & T11 12 & Excellent \\
\hline 7 & 28 & $\mathbf{M}$ & Bilateral & Moderate & Difficult & $\uparrow$ & $\rightarrow$ & $\uparrow$ & $\rightarrow$ & None & 1 year 4 months & Partial block & T12 L1 & Good \\
\hline 8 & 61 & $\mathrm{~F}$ & Bilateral & Severe & Unable to walk & $\uparrow$ & $\uparrow$ & $\uparrow$ & $\uparrow$ & Moderate & 9 months & Partial block & T7 8 & Fair \\
\hline 9 & 75 & $\mathbf{M}$ & Bilateral & Severe & Unable to walk & & $\mathrm{Ab}$ & sent & & Moderate & 3 weeks & Partial block & T11-12 & Fair \\
\hline 10 & 41 & $\mathbf{M}$ & Bilateral & Severe & Unable to walk & $\downarrow$ & $\downarrow$ & Abse & & Moderate & 3 weeks & Partial block & T4 5 & Good \\
\hline 11 & 70 & $\mathbf{M}$ & Bilateral & Moderate & Difficult & $\uparrow$ & $\uparrow$ & $\uparrow$ & $\uparrow$ & Mild & 4 months & Partial block & T6- 7 & Good \\
\hline 12 & 36 & $\mathbf{M}$ & Bilateral & Mild & Difficult & $\uparrow$ & $\uparrow$ & $\uparrow$ & $\uparrow$ & Mild & 10 months & Partial block & T8-9 & Excellent \\
\hline 13 & 44 & $\mathbf{M}$ & Bilateral & Severe & Unable to walk & $\uparrow$ & $\uparrow$ & $\uparrow$ & $\uparrow$ & Moderate & 2 weeks & Partial block & T11 12 & Excellent \\
\hline 14 & 29 & $\mathbf{M}$ & Bilateral & Mild & Difficult & $\uparrow$ & $\uparrow$ & $\uparrow$ & $\uparrow$ & Mild & 11 months & Complete block & T11 12 & Excellent \\
\hline 15 & 68 & $\mathbf{M}$ & Bilateral & Severe & Unable to walk & & Absen & $\downarrow$ & $\downarrow$ & Moderate & 8 months & Partial block & T10-11 & Fair \\
\hline
\end{tabular}

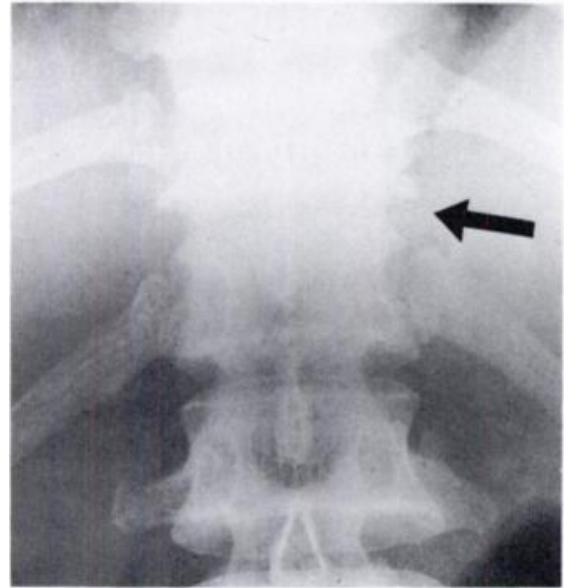

Fig. 2

Anteroposterior radiograph showing narrowed intervertebral disc space between T11 and T12 with osteophytic lipping on the margin.

Radiographic and laboratory evaluation. Radiographs of the thoracic spine, were abnormal in all 15 patients. Narrowing and irregularity of the involved disc space were noted in 12 patients ( 80 per cent). Osteophytic formations adjacent to the involved disc space with a spondylotic vertebral body were also noted in 12 patients $(80$ per cent) (Fig. 2). Localised kyphotic changes were noted in five patients (33 per cent) and calcification of the disc was noted in one (seven per cent). Myodil myelography, by which a positive diagnosis of thoracic disc herniation was made, was performed in all of our patients. Thirteen patients had a partial block, but a complete block was demonstrated in only two patients. Discography was performed in 11 of our patients; however, this is of limited value in thoracic disc herniation. All 11 discograms demonstrated discal degeneration, with evidence of posterior protrusion in three discograms (Fig. 3).

A lumbar puncture was performed in all patients. In five there was evidence of subarachnoid block: in three it was partial and in two complete. The protein content of the cerebrospinal fluid was increased in four patients, varying from 63 to 334 milligrams per 100 millilitres.

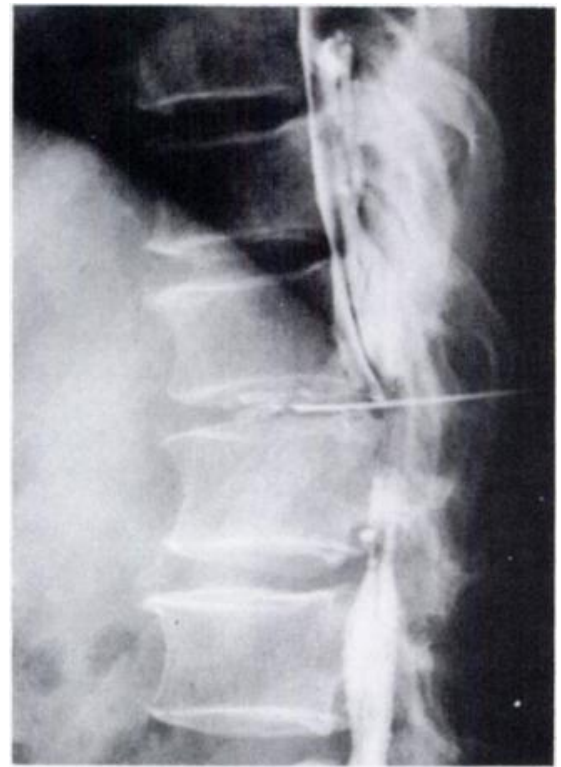

Fig. 3

Lateral discogram showing discal degeneration with evidence of posterior protrusion at the level of T12-L1.

\section{SURGICAL PROCEDURES}

The patient, under general anaesthesia, is placed in the lateral recumbent position with the midportion of the spine flexed in order to afford a good exposure and allow easier removal of the disc. A left-sided anterior approach is usually preferred to make the surgical procedure easier, although either side may be used.

The skin incision is made along the line of the rib which corresponds to one or two vertebrae above the involved disc. The level of the skin incision is chosen by 


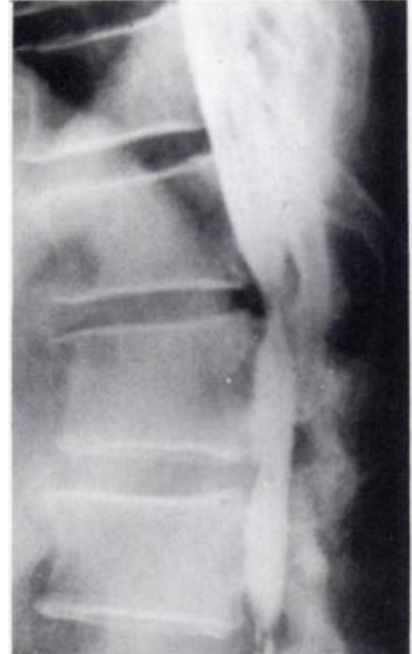

Fig. 4

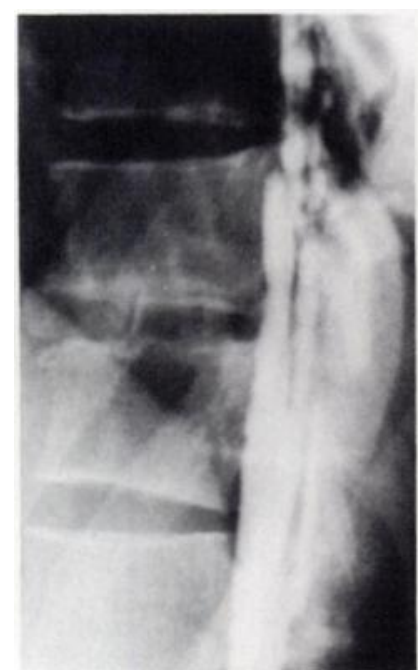

Fig. 5
Figure 4 -Lateral myelogram showing partial block at the level of T11-12. Figure 5- Lateral myelogram of the same patient taken two months after operation, showing no block at the level of T11-12.

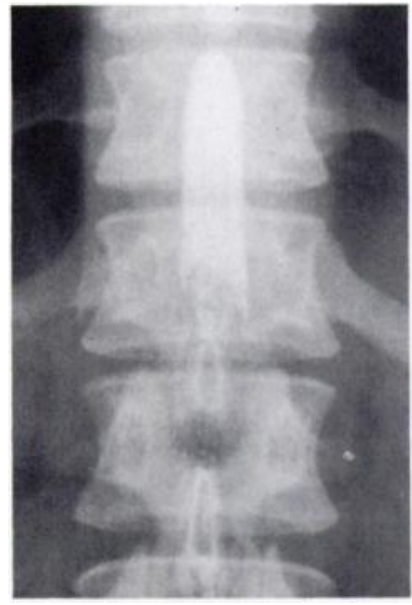

Fig. 6

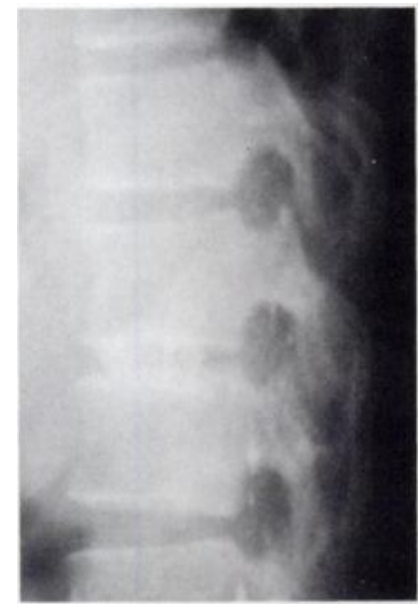

Fig. 7
Figure 6 Anteroposterior myelogram showing complete block at the level of $\mathrm{T} 12-\mathrm{L} 1$. Figure 7-Lateral radiograph of the same patient made five months after operation, showing anterior spinal fusion between $\mathrm{T} 12$ and $\mathrm{Ll}$.

inspection of the anteroposterior radiograph. We prefer an extrapleural approach, since this creates less interference with respiratory function and allows more simplified postoperative care than does a transpleural approach. The pleura is stripped off the chest wall as far as possible. Exposure of the thoracic vertebrae should give adequate access to the front and the opposite side, and one should be able to insert a fingertip into the opposite side. It is preferable to expose the involved disc without disturbing the segmental vessels.

In the thoracolumbar region the skin incision along the line of the tenth rib is extended onto the abdomen. The thoracic vertebrae are exposed by the extrapleural approach, and the lumbar vertebrae are exposed by an extraperitoneal approach. The crura of the diaphragm are cut from the eleventh and twelfth ribs and the transverse process of the first lumbar vertebra.

The involved disc is removed as completely as possible. The anterior longitudinal ligament is also sectioned in order to spread the intervertebral disc space. It may be necessary to resect the disc up to the posterior longitudinal ligament using various ronguers and nibbling forceps. This is best accomplished by spreading the intervertebral disc space with spreaders of various types. After removal of the disc, the cartilage of the vertebral end-plate is removed as completely as possible.

Two pieces of iliac bone graft are inserted into the intervertebral disc space while the space is increased by the spreader. The crura and peripheral attachment of the diaphragm in the thoracolumbar region are repaired with silk. The surgical wounds are closed in layers over a suction drain.

Postoperative care. The suction drain is usually removed after three days and, after removal of the skin sutures, a Risser jacket is applied. The patient is then allowed up and about. The plaster jacket is usually retained for 10 to 12 weeks (Figs 4 to 7).

\section{RESULTS}

The 15 patients who were treated using this procedure were followed up for periods ranging from six months to four years and three months with an average follow-up of two years and two months. The results of surgical treatment were favourable. No patient was made worse but the three patients with a severe neurological deficit had only partial relief of symptoms with some persistent limitation of activity; they were ranked as fair results. These three patients were over 61 years of age and had been incapacitated by almost complete paraplegia for periods of three weeks, eight months, and nine months before operation. Of the remaining 12 patients, seven (47 per cent) had an excellent result, with complete relief of symptoms and a resumption of full activity; and five (33 per cent) had a good result, with complete relief of symptoms but with some residual spasticity or weakness of the legs.

\section{DISCUSSION}

The frequency of symptomatic thoracic disc herniation is low when compared to that of symptomatic cervical and lumbar disc herniations (Love and Kiefer 1950; Logue 1952; Ikeda and Ikeda 1967). During this 11 -year period 15 cases of thoracic disc herniation were observed among a total of 857 disc operations at all levels-an incidence of 1.8 per cent.

In thoracic disc herniation, the gradual onset of clinical manifestations can lead to a delay in diagnosis. The onset of symptoms occurred gradually in 11 of our 15 cases; however, the remaining four had a sudden onset of symptoms of cord compression, accompanied by the prolonged neurological deficit that is commonly encountered in cases of traumatic spinal cord lesions. Early 
diagnosis and early surgical intervention are imperative, especially when symptoms develop rapidly, because the neurological deficits appear to be much more severe (Love and Schorn 1965; Reeves and Brown 1968). The more severe the neurological impairment and the older the patient, the less the improvement that can be expected from the operation.

Reports of decompressive thoracic laminectomy have been made by many authors, pointing out the disappointing results using the traditional posterior approach (Love and Kiefer 1950; Logue 1952; Benson and Byrnes 1975). Access by laminectomy has several disadvantages: the compressive lesion lies anterior to the spinal cord, is commonly median in position and thus only poorly accessible from the back; the spinal cord at the site of compression may be far more vulnerable to damage from relatively minor trauma because of poor vascularity; and with removal of the posterior structures of the spinal column by laminectomy, an abnormal increase in spinal movement can be anticipated.

Crafoord et al. (1958) reported the first use of the transthoracic anterior approach for removal of the disc in the treatment of thoracic disc herniation. After that many other authors reported cases treated by an anterior approach (Ikeda and Ikeda 1967; Perot and Munro 1969; Ransohoff et al. 1969). In 1967, we first attempted a left extrapleural approach to the thoracic vertebrae.

The anterior approach to the thoracic vertebrae for the treatment of disc herniation offers favourable results with minimal surgical intervention (Otani et al. 1977; Albrand and Corkill 1979) and we contend that the anterior approach exclusively should be advocated for the surgical treatment of disc herniation at any level of the spinal cord. We prefer the extrapleural approach to the thoracic vertebrae to prevent postoperative respiratory complications (Otani 1969).

\section{REFERENCES}

Albrand OW, Corkill G. Thoracic disc herniation: treatment and prognosis. Spine 1979;4:41-6.

Benson MKD, Byrnes DP. The clinical syndromes and surgical treatment of thoracic intervertebral disc prolapse. J Bone Joint Surg[Br] 1975; 57-B: $471-7$.

Crafoord C, Hiertonn T, Lindblom K, Olsson S-E. Spinal cord compression caused by a protruded thoracic disc: report of a case treated with antero-lateral fenestration of the disc. Acta Orthop Scand 1958:28:103-7.

Ikeda K, Ikeda A. Anterior spine fusion for thoracolumbar disc herniation. Rinsho Seikei Geka (Japanese) 1967;2:5-13.

Kite WC Jr, Whitfield RD, Campbell E. The thoracic herniated intervertebral disc syndrome. J Neurosurg 1957;14:61-7.

Logue V. Thoracic intervertebral disc prolapse with spinal cord compression. J Neurol Neurosurg Psychiatry 1952; NS 15:227-41.

Love JG, Kiefer EJ. Root pain and paraplegia due to protrusions of thoracic intervertebral disks. J. Neurosurg 1950;7:62-9.

Love JG, Schorn VG. Thoracic-disk protrusions. JAMA 1965;191:627-31.

Otani K. The anterior extrapleural approach to the thoracic spine. Rinsho Seikei Geka (Japanese) 1969;4:505-12.

Otani K, Manzoku S, Shibasaki K, Nomachi S. The surgical treatment of thoracic and thoracolumbar disc lesions using the anterior approach: report of six cases. Spine 1977:2:266-75.

Perot PL Jr, Munro DD. Transthoracic removal of midline thoracic disc protrusions causing spinal cord compression. J Neurosurg 1969;31 452-8.

Ransohoff J, Spencer F, Siew F, Gage L Jr. Transthoracic removal of thoracic disc. J Neurosurg 1969;31:459-61.

Reeves DL, Brown HA. Thoracic intervertebral disc protrusion with spinal cord compression. J Neurosurg 1968;28:24-8.

Tovi D, Strang RR. Thoracic intervertebral disk protrusions. Acta Chir Scand 1960;Suppl 267. 